\title{
Efficacy of Comprehensive Diabetes Care (CDC) Management Program in Elderly Male Patients of Type II Diabetes Mellitus: A Retrospective Study
}

\author{
Rohit Sane ${ }^{1}$, Pravin Ghadigaonkar ${ }^{2}$, Rekha Chaure ${ }^{3}$, Sangeeta Jain ${ }^{3}$, Shweta Wahane ${ }^{4}$, \\ Aarti Nadapude ${ }^{5}$, Aarati Badre ${ }^{3}$, Rahul Mandole ${ }^{1, *}$ \\ ${ }^{1}$ Department of Research and Development, Madhavbaug Cardiac Care Clinics and Hospitals, Mumbai, India \\ ${ }^{2}$ Department of Medical Operations, Madhavbaug Cardiac Care Clinics and Hospitals, Mumbai, India \\ ${ }^{3}$ Madhavbaug Cardiac Care Clinics, Mumbai, India \\ ${ }^{4}$ Madhavbaug Cardiac Care Clinics, Nagpur, India \\ ${ }^{5}$ Madhavbaug Cardiac Care Clinics, Latur, India
}

Email address:

cromilagro@gmail.com (R. Mandole)

${ }^{*}$ Corresponding author

To cite this article:

Rohit Sane, Pravin Ghadigaonkar, Rekha Chaure, Sangeeta Jain, Shweta Wahane, Aarti Nadapude, Aarati Badre, Rahul Mandole. Efficacy of Comprehensive Diabetes Care (CDC) Management Program in Elderly Male Patients of Type II Diabetes Mellitus: A Retrospective Study. International Journal of Diabetes and Endocrinology. Vol. 3, No. 2, 2018, pp. 29-34. doi: 10.11648/j.ijde.20180302.12

Received: August 3, 2018; Accepted: September 7, 2018; Published: October 10, 2018

\begin{abstract}
Globally, Diabetes mellitus (DM) prevalence has created menace, being a major culprit of increased mortality and morbidity and health care expenditures. India is the $2^{\text {nd }}$ country with maximum number of diabetic patients, with an estimated prevalence of around 10\%. Comprehensive Diabetes Care (CDC) is a combination of Panchakarma and Diet management. This study was conducted to evaluate the effect of CDC on glycosylated haemoglobin (HbAlc), body mass index (BMI), body weight, abdominal girth and dependency on conventional therapy in DM Patients. This retrospective study was conducted from July 2017 to January 2018, wherein the data of elderly male type 2 DM patients (HbA1c $>6.5 \%$ ) who attended Madhavbaug clinics in Maharashtra, India were identified. Data of patients who were administered CDC (60-75 minutes) with minimum 6 sittings over 90 days ( \pm 15 days) were considered. Variables were compared between day 1 and day 90 of CDC. Out of 48 enrolled elderly male patients, 34 were included for analysis. CDC showed significant improvement in HbA1c from $8.27 \pm$ 0.96to $7.1 \pm 1.30 ; \mathrm{p}=0.0001$ ), BMI from $27.65 \pm 3.20$ to $25.91 \pm 3.29$, $\mathrm{p}<0.0001$ ), weight from $73.75 \pm 10.76$ to $69.46 \pm 10.39$, $\mathrm{p}<0.0001$ ). Abdominal girth (from $100.0 \pm 9.08$ to $95.36 \pm 9.10 ; \mathrm{p}<0.0001$ ), also showed significant reduction. Dependency on concomitant medicines was reduced, with number of patients on no concomitant medicines increasing from $3 \%$ to $15 \%$. CDC and allopathy both are found to be efficacious; but CDC acts dually, by reducing $\mathrm{HbAlc}$, as well as reducing dependency on allopathic medications.
\end{abstract}

Keywords: Comprehensive Diabetes Care, CDC, Panchakarma, HbA1C, BMI, DM, Alternative Medicine

\section{Introduction}

Diabetes mellitus type II (DM) prevalence has reached epidemic levels in global scale. International diabetes federation quotes that number of diabetics in 2030 will rise by estimated 200 million rise in number of cases, as compared to prevalence in 2011 [1]. This is far more concerning in India, where it is estimated that around $1 / 10^{\text {th }}$ of the population is inflicted by DM, with significantly high mortality rates [2, 3]. Historically, fasting blood sugar level $>126 \mathrm{mg} / \mathrm{dl}$ and post-meal blood sugar level $>140$ $\mathrm{mg} / \mathrm{dl}$, which together constitute an oral glucose tolerance test is used for diagnosis of DM. Nowadays, glycosylated hemoglobin $(\mathrm{HbAlc})$ is used for diagnosis of DM, as it depicts blood glucose levels over preceding 2-3 months. $\mathrm{HbAlc}$ levels $>6.5 \%$ is diagnostic of DM, while levels less 
than 6.5 but more than $5.7 \%$ are considered as prediabetics. Most of the guidelines suggest target $\mathrm{HbA1c}$ as $\leq 6.5 \%$ [4]. Plethora of complications of DM, grouped as macrovascular and microvascular, short term and long term, makes the disease more dangerous. Stroke, myocardial infarction, peripheral vascular disease are some of the macrovascular complications, while retinopathy, neuropathy and nephropathy are grouped under microvascular complications. However, major culprit for morbidity and mortality in diabetic patients is cardiovascular diseases (CVD) [5]. Foot ulcers, amputations are some of the after effects of diabetic neuropathy, while diabetic nephropathy is one of the major cause of morbidity and mortality in diabetic patients after CVD [6-9]. Diabetes is presently managed by advocating dietary corrections and regular physical exercise along with treatment with oral antidiabetic drugs/oral hypoglycemic agents (OADs). It is recommended to start OAD only when diet management and other measures are unable to bring down levels of HbAlc to $<6.5 \%$ after 2 months. The majority of the OADs act by either, reducing the intrinsic glucose production, increasing tissue uptake or increasing excretion. Sulphonylureas, thiazolidinedione, biguanides, etc. are some of the examples of conventional class of antidiabetic drugs. When $1 \mathrm{OAD}$ is unable to reduce the $\mathrm{HbA} 1 \mathrm{c}$ below $7.5 \%$ or if baseline $\mathrm{HbA} 1 \mathrm{c}$ is too high, it is recommended to use combination of OADs from different class [10]. But, major issues faced with the use of OADs are a plethora of adverse effects which include hypoglycemia, pancreatitis, anemia, etc [11]. These adverse effects along with the increased cost of therapy has found to drastically reduce medication adherence in patients of DM [12]. Despite the availability of numerous classes of OADs and extensively laid down guidelines, number of cases of DM are consistently increasing [12]. Thus, an effective alternative therapy is needed, that will counteract these adverse effects of conventional medicines and increase patient adherence to medications for optimal outcome. OADs act by reducing blood sugar levels in the body. Various herbal drugs have shown similar effects in clinical studies, including significant reduction in HbA1c [13-15]. This makes Ayurveda a potential therapeutic alternative in patients of type 2 DM. Ayurvedic physicians advocate Panchakarma- a multi-step body detoxification process in the chronic phase of disease. Panchakarma and diet therapy is combined in Comprehensive Diabetes Care (CDC) Management Program. Three techniques are used in Panchakarma in CDC-Snehana i.e. oleation, Swedana i.e. passive heat therapy and Basti i.e. per rectal drug administration. Panchakarma is a well-known procedure for internal detoxification of the body [16-17]. Since reduction in quality of life, depression are associated with $\mathrm{DM}$, we planned this retrospective study in elderly male patients of type $2 \mathrm{DM}$, to assess the efficacy of CDC on various parameters like $\mathrm{HbA1c}$, BMI, reduction in body weight, abdominal girth and reduction in dependency on conventional medications after completion of CDC.

\section{Subjects and Methods}

\subsection{Study Design}

Retrospective record based study.

\subsection{Study Site}

\section{Madhavbaug Clinics from all over Maharashtra}

\subsubsection{Study Period}

July 2017 to January 2018.

\subsubsection{Study Participants}

Elderly male ( $>60$ years), suffering from type $2 \mathrm{DM}$ (HbA1c $>6.5 \%),{ }^{[4]}$ who attended Madhavbaug clinics across Maharashtra.

\subsubsection{Methodology}

The data of patients who had been administered CDC with minimum 6 sittings over a span of 90 days ( \pm 15 days) were considered for the study, out of which 4 sittings were done in the $1^{\text {st }}$ month, and 1 sitting per month for next 2 months. These patients were maintained on a diet plan of 800-1000 calories intake per day, according to patient medical records. The diet plan consisted of low carbohydrates, moderate proteins, and low fats. Cases were identified, and data was assessed from the records of Madhavbaug clinics in Maharashtra. The selection was based upon the availability of complete relevant baseline data (day 1 of CDC) and final day data (day 90 of CDC) of the patients. The information about prescribed concomitant medicines, if any, was also noted down. On day 1 of $\mathrm{CDC}$, the patients had undergone HbA1c, weight, BMI, abdominal girth measurements as per guidelines [18]. This readings were considered as baseline reading. This process was repeated on day 90 of CDC to calculate the change from baseline reading. The BMI for day 1 and day 90 of the patients was calculated by checking the weight and the height from the medical data sheets of patients and using the formula: weight in kilograms/ (height in meters $)^{2}$. The dependency on standard medication was calculated both on day 1 and day 90 of CDC as the percentage of patients out of the total enrolled ones who required a conventional allopathic therapeutic agent during the study period of 90 days.

The CDC is a 3-step procedure which was performed on the patients of type $2 \mathrm{DM}$ after a light breakfast. One sitting of the procedure took 65-75 minutes, as described in table 1 [19-20].

Table 1. Study Treatment: Comprehensive Diabetes Care (CDC).

\begin{tabular}{llll}
\hline Step of CDC & Type of Therapy & Herbs used for therapy & Duration of Therapy \\
\hline \multirow{2}{*}{ Snehana } & $\begin{array}{l}\text { Massage or external oleation (centripetal } \\
\text { upper strokes on the body) }\end{array}$ & $\begin{array}{l}100 \mathrm{ml} \text { Azadirechta indica (neem) extract processed in } \\
\text { sesame oil }\end{array}$ \\
Swedana & Passive heat therapy to the body & Dashmoola (group of ten herbal roots) with steam at $\leq 40$ \\
\hline
\end{tabular}




\begin{tabular}{|c|c|c|c|}
\hline Step of CDC & Type of Therapy & Herbs used for therapy & Duration of Therapy \\
\hline & & degrees Celsius) & of relaxation after procedure \\
\hline Basti kadha & $\begin{array}{l}\text { Per-rectal drug administration should be } \\
\text { in body for } \geq 15 \text { minutes for maximum } \\
\text { absorption }\end{array}$ & $\begin{array}{l}\text { Mixture of } 40 \% \text { Gudmaar (Gymnema sylvestre), } 20 \% \\
\text { Daruharidra (Berberis aristate) and } 40 \% \text { Yashtimadhu } \\
\text { (Glycyrrhiza glabra) }\end{array}$ & 10 minutes \\
\hline
\end{tabular}

\subsubsection{Statistical Analysis}

Data were pooled and coded in Microsoft Excel spreadsheet. R Version 3.4.1 software was used to analyze the data. Categorical data were represented in the frequency form and continuous data were presented as the Mean \pm SD. Paired t-test was used to assess the difference between baseline values and $90^{\text {th }}$ day after treatment. The histogram were used to represent the graphs.

\section{Results}

Study population:

A total of 48 patients' data was screened for inclusion in the study. However, based on the availability of data (Day 1 and Day 90) and the inclusion criteria, 34 patients were selected, and their data was considered for analysis. The present study involved a total of 34 male patients with more than 60 years age having a diabetic history and $\mathrm{HbAlc} \geq 6.5$. The mean age of the patients was $66.32 \pm 4.86$ years and mean height was $163.34 \pm 6.53 \mathrm{~cm}$.

Clinical parameters compared between baseline values and after $90^{\text {th }}$ day was as shown in Table 2. After 90 days of treatment there was significant reduction in the $\mathrm{HbAlc}$ $(P=0.0001$; Figure 1). There was significant reduction in weight ( $\mathrm{P}<0.001$; Figure 2), BMI $(\mathrm{P}<0.0001$; Figure 3$)$ and Abdomen girth $(\mathrm{P}<0.0001$; Figure 4$)$ post treatment of 90 days.

Table 2. Comparison of clinical parameters between baseline values and $90^{\text {th }}$ day.

\begin{tabular}{|c|c|c|c|c|}
\hline Variable $(n=34)$ & Baseline & After 90 days & t statistic & p-value \\
\hline $\mathrm{HbA1c}$ & $8.27 \pm 0.96$ & $7.1 \pm 1.30$ & 4.71 & 0.0001 \\
\hline Weight (Kg) & $73.75 \pm 10.76$ & $69.46 \pm 10.39$ & 10.964 & $<0.0001$ \\
\hline BMI & $27.65 \pm 3.20$ & $25.91 \pm 3.29$ & 7.35 & $<0.0001$ \\
\hline Abdomen girth $(n=25)$ & $100.0 \pm 9.08$ & $95.36 \pm 9.10$ & 8.1 & $<0.0001$ \\
\hline
\end{tabular}

HbA1c; Glycated haemoglobin, BMI; Body mass index

Table 3. Correlation of BMI and Abdomen girth with HbAlc at $1^{\text {st }}$ day and after 90 days.

\begin{tabular}{lllll}
\hline \multirow{2}{*}{ Correlation between } & Baseline & & After 90 days & p \\
\cline { 2 - 4 } & R & p-value & r & 0.07 \\
\hline BMI and HbA1c & 0.05 & 0.76 & 0.69 & 0.05 \\
Abdomen girth and HbA1c & -0.049 & 0.82 & 0.81 \\
\hline
\end{tabular}

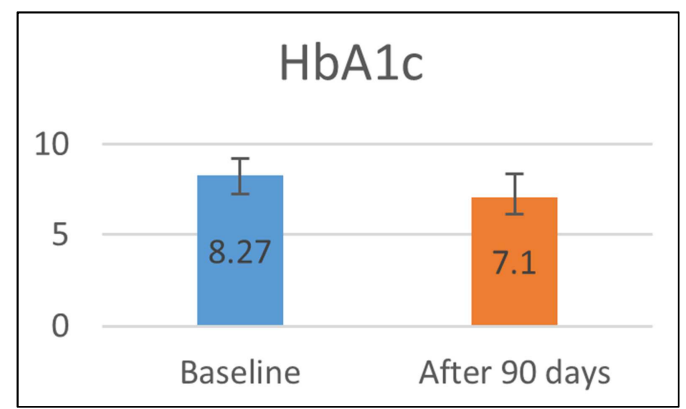

Figure 1. Comparison of HbAlc at baseline and after 90 days.

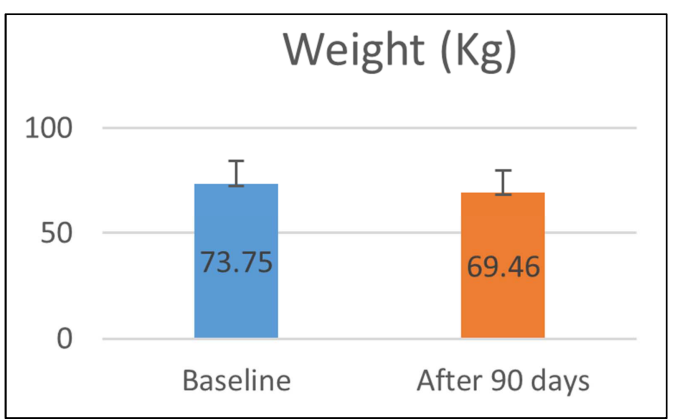

Figure 2. Comparison of weight of the patients at baseline and after 90 days.

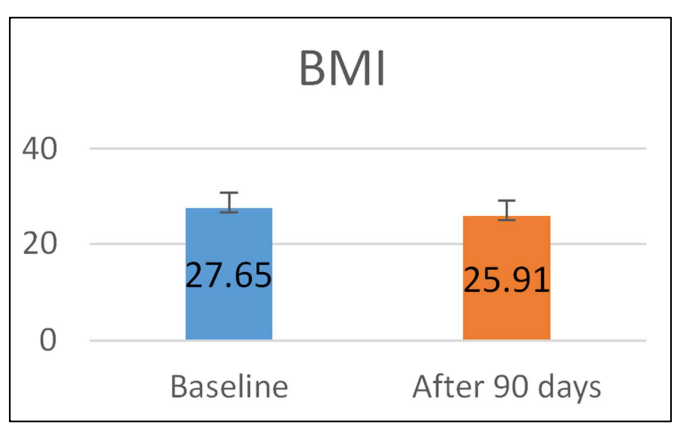

Figure 3. Comparison of BMI of the patients at baseline and after 90 days.

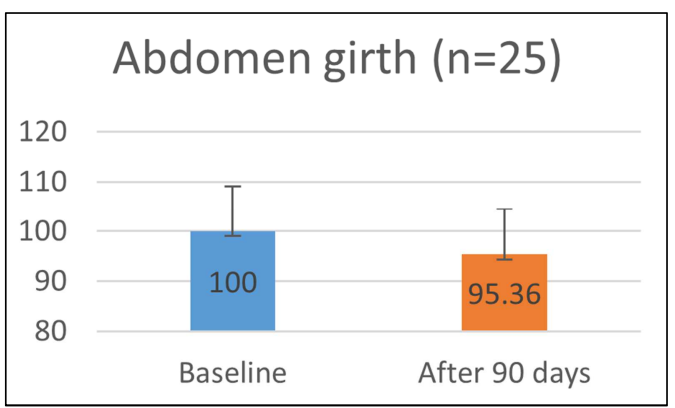

Figure 4. Comparison of Abdomen girth of the patients at baseline and after 90 days. 
We also assessed the correlation between the BMI and $\mathrm{HbA1c}$, abdominal girth and HbA1cb (table 3). There was a weak positive correlation between BMI and $\mathrm{HbAlc}(\mathrm{r}=0.05)$ on the 1 st day of the treatment and it was not statistically significant $(\mathrm{p}=0.06)$, the same is shown in figure 5a. After 90 days of treatment we found nearly same positive relationship between BMI and HbA1c $(r=0.07, p=0.70)$ which is shown

\section{a : BMI \& HbA1c at 1st day}

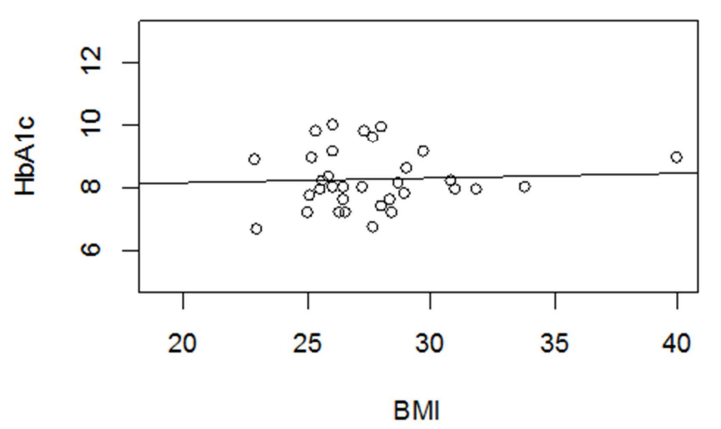

\section{$C:$ HbA1c \& Abdomen Girth at 1st day}

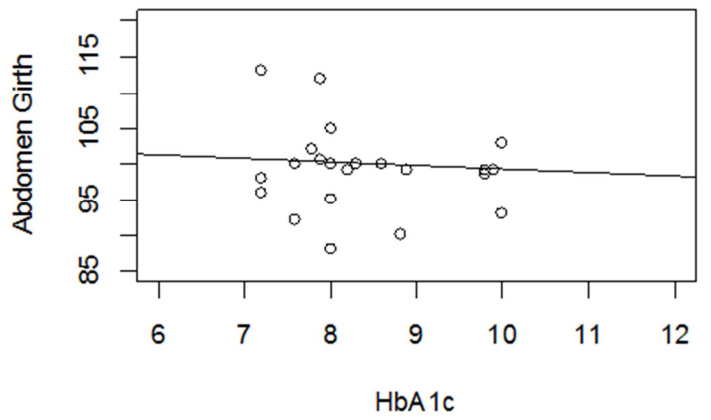

in figure $5 b$.

We found a negative relationship between $\mathrm{HbA1c}$ and abdomen girth $(\mathrm{r}=-0.049)$ on the $1 \mathrm{st}$ day of the treatment which was not statistically significant $(\mathrm{p}=0.82$ ) (figure $5 \mathrm{c}$ ). We found a weak positive relationship between them after the treatment $(\mathrm{r}=0.051)$ on day 90 , and it was not statistically significant $(\mathrm{p}=0.81)$ (figure $5 \mathrm{~d})$.

\section{b: BMI \& HbA1c at 90th day}

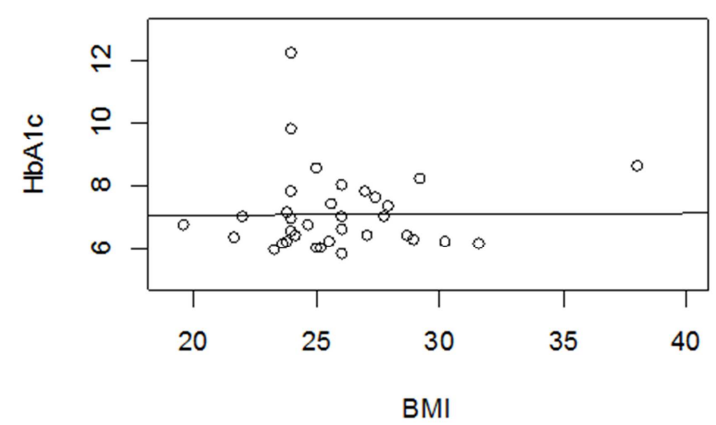

\section{d : HbA1c \& Abdomen Girth at 90th day}

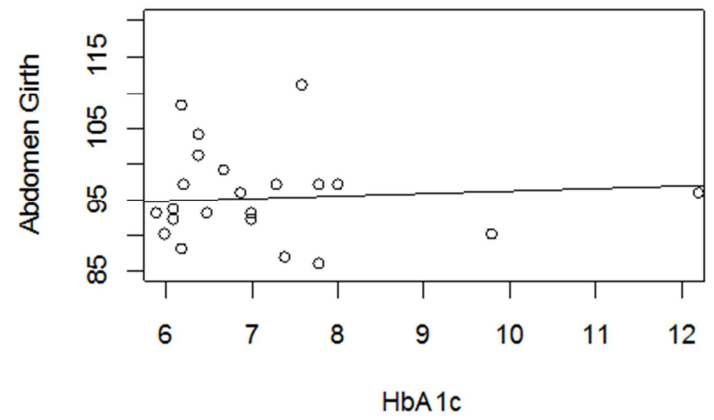

Figure 5. Correlation between BMI and HbAlc, abdomen girth and HbAlc.

Allopathic medicines consumption on day 1 and after the $90^{\text {th }}$ day of therapy were as shown in Table 4 . Most of the enrolled subjects were treated with biguanides (58.82\%), sulfonylurea (38.24\%), nonsteroidal anti-inflammatory drugs $(35.29 \%)$, statin $(29.41 \%)$. All the subjects who were allopathic medicines before therapy was decreased after $90^{\text {th }}$ day. However, the subjects with nonsteroidal antiinflammatory drugs were not varied after the therapy. An illustration is given in figure 6 .

Table 4. Consumption of allopathic medicines on day 1 and after 90 days.

\begin{tabular}{lll}
\hline Medicine & Day $\mathbf{1}$ & After 90 days \\
\hline Sulfonylurea & $13(38.24)$ & $10(29.41)$ \\
Biguanide & $20(58.82)$ & $13(38.24)$ \\
Thiazolidinedione & $4(11.76)$ & $2(5.88)$ \\
DPP-4 inhibitor & $8(23.53)$ & $5(14.71)$ \\
Alpha-glucosidases inhibitors & $5(14.71)$ & $3(8.82)$ \\
Insulin & $3(8.82)$ & $3(8.82)$ \\
NSAID & $12(35.29)$ & $12(35.29)$ \\
Statin & $10(29.41)$ & $6(17.65)$ \\
ARB & $8(23.53)$ & $6(17.65)$ \\
Beta blocker & $5(14.71)$ & $2(5.88)$ \\
CCB & $6(17.65)$ & $5(14.71)$ \\
Antiplatelet & $7(20.59)$ & $7(20.59)$ \\
Nitrate & $1(2.94)$ & $1(2.94)$ \\
No medicine & $1(2.94)$ & $5(14.71)$ \\
\hline
\end{tabular}




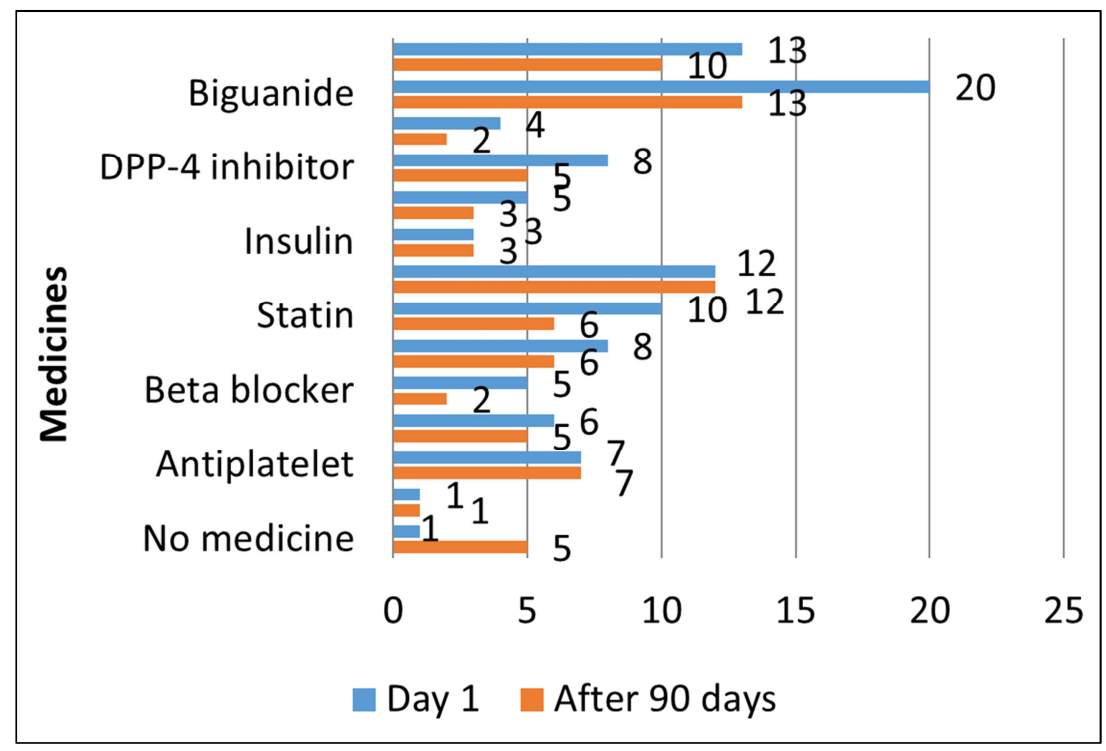

Figure 6. Comparison of consumption of allopathy medicine at $1^{\text {st }}$ day and after 90 days.

\section{Discussion}

Despite the availability of a plethora of therapeutic options for treatment of type II DM, its prevalence and contribution to global morbidity and mortality remains significantly high and is increasing continuously. Therefore, alternate therapeutic option to curb the menace of DM is the urgent necessity of current time. Conventionally used allopathic medicines in the treatment of type II DM act by reducing blood sugar levels. Ayurvedic medicines serves as a potential alternate therapeutic option for management of type II DM, since many herbal drugs have been found to significantly lower blood glucose levels in clinical studies. Ayurvedic physicians administer Panchakarma to the patients of DM [16]. Panchakarma along with diet therapy consisting of low carbohydrates and fats with moderate amount of proteins is administered in CDC. Probable mechanism, by which CDC might benefit patients with type II DM are:

1. Reducing glucose production in the liver by hampering sympathetic stimulation on gluconeogenesis,

2. Reducing the shear stress of vascular endothelium by promoting water loss via sweating. This may help in reducing vascular complications significantly [16].

In the present study, the CDC was found to significantly reduce $(\mathrm{p}<0.001) \mathrm{HbA1c}, \mathrm{BMI}$, body weight, abdominal girth, at the end of study period i.e. $90^{\text {th }}$ day. Another crucial finding of our study was that there was significant reduction in patients' dependency on conventional allopathic antidiabetic medications at the end of the study period.

HbAlc value is one of the most crucial parameter in diabetic patients as it echoes blood sugar level control over preceding 2-3 months [4]. Another important feature of $\mathrm{HbA} 1 \mathrm{c}$ is its prognosticator value in type $2 \mathrm{DM}$, since it has been found that morbidity and mortality is directly related to sustained increased HbA1c [21]. Thus it can be anticipated from the findings of our study that CDC carries a good prognosis in diabetic patients as it significantly reduces
HbA1c. Obesity and sedentary lifestyle contribute to development of DM, which is indicated by increased BMI [22]. Apart from DM, high BMI has epidemiological linkage with many chronic diseases like HTN and other CVDs [23]. Sustained control of blood sugar levels is the utmost important factor in diabetic patients, since it has been established that poor blood sugar level control is associated with increased incidence of complications [24]. CDC can help in reducing complications of DM since it showed sustained reduction in all parameters like $\mathrm{HbAlc}$, BMI, body weight, etc.

Another major issue with the use of conventional drugs is increased cost of therapy along with increased incidence of adverse effects associated with use of these drugs [25]. Hence, we assessed the effect of CDC on dependency on conventional medications. In our present study, we found that there was an overall reduction in dependency of patients on conventional medications at the end of the study period. Also, the number of patients who went off the conventional drugs increased at the end of $90^{\text {th }}$ day.

In order to generalize the findings of our study to the larger population, we recommend conduction of similar studies with dual arms, to allow direct comparison with conventional therapy, prospective design, and long follow up period with larger sample size.

\section{Conclusion}

Major parameters of the body deranged in DM are BMI, body weight, abdominal girth all of which worsen complication rate. Although conventional correct these parameters to some extent, cost of therapy and adverse effects offset their beneficial effects and decrease patient compliance. CDC corrected all these parameters effectively and also reduced dependency on conventional drugs, all of which have positive contributory effect on enhancing patient compliance. Thus it is safe to conclude that CDC can be 
considered as effective and safe therapeutic option for treatment of DM.

\section{Acknowledgements}

The authors thank the study participants and their families, without whom this study would not have been accomplished

\section{References}

[1] Unwin N, Whiting D, Guariguata L, Ghyoot G, Gan D (Eds). The IDF Diabetes Atlas, 5th edition. Brussels, Belgium: International Diabetes Federation; 2011. pp. 7-12.

[2] Vijayakumar G, Arun R, Kutty V. High Prevalence of Type 2 Diabetes Mellitus and Other Metabolic Disorders in Rural Central Kerala. JAPI. 2009; 57:563-7.

[3] Singh PS, Sharma H, Zafar K, et al. Prevalence of type 2 diabetes mellitus in rural population of India- a study from Western Uttar Pradesh. Int J Res Med Sci 2017; 5:1363-7.

[4] Verma M, Paneri S, Badi P, et al. Effect of increasing duration of diabetes mellitus type 2 on glycated hemoglobin and insulin sensitivity. Indian Journal of Clinical Biochemistry, 2006, 21 (1): $142-146$.

[5] Kaveeshwar SA, Cornwall J. The current state of diabetes mellitus in India. AMJ 2014, 7, 1, 45-48.

[6] Ramachandran A. Type 2 diabetes in India: Challenges and possible solutions. Retrieved from http://www.apiindia.org/medicine_update_2013/chap40.pdf. [last accessed on $3^{\text {rd }}$ June 2018].

[7] Tripathi K, Srivastava A. Diabetes mellitus: Complications and therapeutics. Med Sci Monit, 2006; 12 (7): RA130-147.

[8] Silva E, Ferriera C, Pinho L. Risk factors and complications in type 2 diabetes outpatients. Rev Assoc Med Bras 2017; 63 (7):621-627.

[9] Complications of diabetes mellitus. Retrieved from http://semmelweis.hu/belgyogyaszat3/files/2017/05/Complicat ions-of-diabetes-mellitus.pdf [last accessed on April 21 2018].

[10] Matthaei S, Bierwirth R, Fritsche A, et al. Medical Antihyperglycaemic Treatment of Type 2 Diabetes Mellitus. Exp Clin Endocrinol Diabetes 2009; 117: 522 - 557.

[11] Meneses M, Silva B, Sousa M, et al. Antidiabetic Drugs: Mechanisms of Action and Potential Outcomes on Cellular Metabolism. Current Pharmaceutical Design. 2015; 21 (25): 3606-3620.

[12] Egede L, Axon R, Gebregziabher M, et al. Medication Nonadherence in Diabetes. Diabetes Care. 2012; 35:25332539 .
[13] Elder C, Aickin M, Bauer V et al. Randomized Trial of a Whole-System Ayurvedic Protocol for Type 2 Diabetes. Alternative Therapies in Health and Medicine. 2006; 12 (5): 24-30.

[14] Vidyashree K, Prasad K, Shilpa A. Role of Panchkarma in madhumeha w.s.r. to type 2 diabetes mellitus: a review. International Ayurvedic Journal. 2018; 6 (4): 835-840.

[15] Choudhary U, Pandey A. A clinical assessment of the role of panchakarma therapy in the care of young prediabetics. International Journal of General Medicine and Pharmacy. 2013; 2 (1): 15-24.

[16] Giri S, Patnaik S, Kumar K, et al. Potential of ayurvedic panchakarma in prevention and management of lifestyle disorders with special reference to madhumeha, J of Ayurveda and Hol Med (JAHM). 2015; 3 (5):82-91.

[17] Nair D. Understanding the Role of Ayurveda Panchakarma Therapy W. S. R. to Vasthi (Enema) in the Management of Type II Diabetes Mellitus- A Case Review. Int J Complement Alt Med. 2017; 8 (6): 00276.

[18] Definition and diagnosis of diabetes mellitus and intermediate hyperglycemia. Retrived from http://www.who.int/diabetes/publications/Definition\%20and\% 20diagnosis\%20of\%20diabetes_new.pdf [Last accessed on Dec $\left.21^{\text {st }} 2017\right]$.

[19] Uebaba K, Xu F, Ogawa H, et al. Psychoneuroimmunologic effects of ayurvedic oil dripping treatment. J Altern Complement Med. 2008; 14:1189-1198.

[20] Sane R, Aklujkar A, Patil A, Mandole R. Effect of heart failure reversal treatment as add-on therapy in patients with chronic heart failure: A randomized, open-label study. Indian Heart Journal. 2017; 69 (3): 299-304.

[21] "Clinical importance of Glycosylated hemoglobin (HbAlc) in diabetes mellitus patients". Retrievedfrom https://www.researchgate.net/publication/26575867_Clinical Importance_Of_Glycosylated_Hemoglobin_HbA1c_In_Diabe tes_Mellitus_Patients. [Last accessed on march $11^{\text {th }} \overline{2}$ 2018].

[22] Dua S, Bhuker M, Sharma P, Dhall M, Kapoor S. Body mass index relates to blood pressure among adults. North Am J Med Sci 2014; 6:89-95.

[23] Danasekaran R, Vinoth R. A study on relation between BMI and hypertension among adolescents in Kancheepuram district, Tamil Nadu. IJAR. 2015; 1 (2): 8-12.

[24] Chaudhury A, Duvoor C, Reddy V, et al. Clinical Review of Antidiabetic Drugs: Implications for Type 2 Diabetes Mellitus Management. Front. Endocrinol. 2017; 8 (6):1-12.

[25] Perwitasari D, Urbayatun S. Treatment Adherence and Quality of Life in Diabetes Mellitus Patients in Indonesia. Sage Open. 2016:1-7. 